\title{
Managing Digital Transformation with Sociotechnical Micro-Foundations: A Dynamic Capabilities Approach
}

\author{
Jon Iden \\ NHH Norwegian School of Economics \\ jon.iden@nhh.no
}

\author{
Bendik Bygstad \\ University of Oslo \\ bendikby@ifi.uio.no
}

\begin{abstract}
The dynamic capabilities approach has contributed to our understanding of digital transformation and has been complemented with the concept of micro-foundations. However, the potential contribution of micro-foundations has not fully been realized in IS research to explain the dynamics of digital transformation. Thus, we introduce sociotechnical micro-foundations, which we posit in an empirically grounded theoretical framework through an in-depth case study of the digital transformation of a Nordic hotel chain. The proposed framework advances the literature on dynamic capability and digital transformation by extending our understanding of how competencies and digital resources are interrelated in digital transformations.
\end{abstract}

\section{Introduction}

Managing a digital transformation is a challenging process that requires a combination of capabilities and resources, particularly in incumbent firms. The role of a digital transformation is to gain or maintain competitive advantage and satisfy stakeholders by leveraging digital technologies. Digital transformations also entail changes in strategy [1], organizational structures [2], services and products [3], and business models [4]. However, less is known about which capabilities are necessary for a digital transformation. The recent literature review by Vial [5] called for more studies that employ dynamic capabilities in relation to digital transformation. The dynamic capability perspective has been extensively used in strategic and change management literature to investigate how companies create, extend, or modify their resources in response to rapidly changing environments [6]. Dynamic capabilities enable firms to transform through three capacities: sensing, seizing, and reconfiguring [7]. This concept has also been adopted in Information Systems research to investigate how organizations leverage digital technologies to overcome environmental challenges and compete successfully [8].

The dynamic capabilities concept has been refined by drawing on micro-foundations, which are broadly defined as specific skills, processes, organizational structures, decision-making rules, and learning mechanisms needed to support and sustain dynamic capabilities [9]. For instance, to sense changes in the environment, organizations need people with specific competencies and tools to collect relevant information and analyze it. While the micro-foundation concept helps understand how dynamic capabilities are supported, it is not sufficiently developed in terms of technology. Although the idea of sociotechnical micro-foundations is not new (e.g., $[10,11])$, it has not been conceptualized into a theoretical construct. This is unfortunate, because to explain digital transformation, we need to understand how combinations of social and technological elements interoperate to create outcomes [12]. The current research on dynamic capabilities can be further extended and complemented to include the notion of sociotechnical micro-foundations. This led us to the following research question: How can we conceptualize and theorize a sociotechnical micro-foundation concept?

To investigate this question, we assessed extant research on dynamic capabilities and micro-foundations and building on sociotechnical IS research, we developed the sociotechnical micro-foundation concept. Then we conducted an in-depth case study of the digital transformation of a large hotel chain over a five-year period. In analyzing this case, we identified the sociotechnical micro-foundations in each of the three capacities that enabled the hotel chain's digital transformation. Based on our review of the literature and the case analysis, we developed a framework for sociotechnical micro-foundations. In doing so, we extend the digital transformation literature by revealing the micro-level mechanisms necessary for building and maintaining dynamic capabilities for the transformation.

This paper is organized as follows. First, we present the theoretical background. Second, we describe the research setting and detail how we collected and analyzed data. Third, we offer analyses and findings, providing the empirical evidence that allows us to explore and posit sociotechnical micro-foundations in a theoretical framework. Fourth, we discuss how the findings extend current research on dynamic capabilities and digital transformations. Last, we conclude with theoretical and practical implications. 


\section{Theoretical background}

\subsection{Contextual background}

The contextual background for this study is digital transformation, a process where organizations set out to transform their business through combining and utilizing digital technology and data. Digital transformation has been defined in various ways [5], but some characteristics are discovered. Digital transformation is driven by external factors, such as intensified competition, and/or by the opportunities emerging from new technologies, such as digital platforms, apps, big data, analytics, artificial intelligence, the internet of things, and robotics [13]. Based on such insights, and to initiate the transformation process, firms develop digital business strategies [1]. Firms may also nominate chief digital officers (CDOs) and establish digital innovations units to initiate, coordinate, and oversee the activities [14]. New skill sets are required to adopt, master, and manage the new digital technologies, and to integrate the technologies in processes, services, and products [15]. Cultural changes may also be necessary, as a digital transformation requires an organizational environment where employees are eager to continuously learn and gain digital experiences [16] and are willing to change their work practices accordingly [17]. Literature reveals that a digital transformation takes time, often many years. The transformation is not the result of one digitalization project alone, but of a combination of various digital and organizational changes that follow in time [18].

What makes a digital transformation fundamentally different from other IT change efforts is that it entails more than improving the status quo through the implementation of new technologies in existing operations, products, and services. A digital transformation requires deep and substantial organizational changes, which affect the routines, knowledge, and capabilities of members at all levels. It involves the transformation of business models and organizational structures to create a new organizational identity [19]. Organizational scholars have long agreed that "substantial organizational change is disruptive, often requiring revisions in fundamental assumptions, interpretations, knowledge, language, actions, and practices at individual and collective levels" [20, p. 365].

\subsection{Dynamic capabilities}

The dynamic capability perspective can help explain how firms thrive and sustain competitive advantage in response to changing environments [7]. Teece et al. [6] advocated the concept for environments that are open to international commerce, where technical change is systemic, where the global market for goods and services is well developed, where technological and managerial knowledge is poorly developed, and when regulatory or institutional shocks occur. In such environments, a dynamic capability is a firm's potential to systematically solve problems, formed by the firm's propensity to sense opportunities and threats, make timely and marketoriented decisions, and change its resource base [9]. This capability should be repeatable to distinguish it from a one-time change [21]. Recent studies have focused increasingly on how this body of literature can be employed by IS researchers to explain how and why organizations invest in digital technologies [22], as well as how dynamic capabilities can support a firm's ongoing digital transformation [5].

In this study, we adopt Teece et al.'s [6, p. 516] definition of dynamic capabilities as "the firm's ability to integrate, build, and reconfigure internal and external competences to address rapidly changing environments." These competences denote managerial and organizational processes by which the organization achieves new and innovated forms of sustained competitive advantage [6]. Teece et al. [6] assumed that dynamic capabilities are typically built rather than bought, and that they are essentially firm-specific and unique. Dynamic capabilities enable companies to identify new opportunities and redirect or develop their resources to meet new challenges [6,7]. In this respect, resources are "stocks of available factors that are controlled by the firm," whereas capabilities "refer to a firm's capacity to deploy resources" [23, p. 35], using individuals, processes, or structures [24].

According to Teece [7], dynamic capabilities enable firms to transform through three capacities: sensing, seizing, and reconfiguration. In the digital transformation context, sensing involves the ability to look beyond current operations, understand environmental changes and challenges, and assess technological opportunities in relation to customers' changing needs. Seizing includes the mobilization of skills and resources to take advantage of opportunities. Reconfiguration is the continued renewal of the firm and its resources, and includes the ability to mobilize, motivate, and inspire employees to favor ongoing change [9].

\subsection{Sociotechnical micro-foundations}

To support and sustain the three capacities, organizations must develop and maintain what Teece [7] explicated as micro-foundations, such as specific skills, processes, organizational structures, decision-making rules, and learning mechanisms [9]. For example, organizations need analytic competencies to identify threats and opportunities, and they need processes and structures to seize and reconfigure their resource bases for sustained competitive advantage. This approach has 
been very useful in understanding how dynamic capabilities are developed and sustained: for instance, how employee motivation and engagement play a crucial role in establishing dynamic capabilities [25]. These micro-foundations are very useful, but in the context of digital transformation, the technological dimension should be more explicit. What is needed are sociotechnical micro-foundations that include organizational and technical aspects. We agree with Jensen and Bækgaard [11], who claimed that organizational and technological capabilities should be combined to build a strong foundation for competitive action within an organization.

In developing a sociotechnical concept, we build on three basic insights from the literature. First, a sociotechnical perspective assumes that modern organizations should be understood not as purely social, but as interacting networks of people and technologies, executing roles and tasks to attain their goals [26]. Second, digital transformation literature has shown that two key elements are competencies and digital resources, which decide what the organization is capable of [1]. Third, a sociotechnical micro-foundation can be seen as similar to an affordance, broadly defined as a possibility for action and specifically, "the potential for behaviors associated with achieving an immediate concrete outcome and arising from the relation between an object and a goal-oriented actor or actors" [27].

Building on these insights, we define a sociotechnical micro-foundation as "the combination of organizational competencies and a digital resource that enables the organization to realize a specific type of task" The term combination expresses that this microfoundation is not an attribute of the organizational actor or of technology, but an emergent quality. A digital resource can be a tool, such as a machine learning algorithm, or a large structure, such as a digital platform. A specific type of task indicates that the sociotechnical micro-foundation is goal-directed; it addresses a particular task or need. Sociotechnical micro-foundations are capacities directed toward a specific digital resource, such as analyzing, identifying, developing, innovating, establishing, launching, and redesigning digital resources. The syntax of a sociotechnical micro-foundation typically is actor $X$ can utilize $Y$ to achieve $Z$. We explore and assess this understanding in this case study.

\section{Method and case}

\subsection{Research setting and business context}

To analyze and theorize sociotechnical microfoundations, we adopted a longitudinal research strategy [28] and investigated the digital transformation of a large hotel chain over a five-year period. Qualitative, in-depth longitudinal case studies are well- suited to generating understanding of how a phenomenon emerges and develops over time [29], as well as to developing a theory that is rigorous and context-sensitive [30]. We selected a large hotel chain for two reasons. First, the hospitality industry offers an opportunity to investigate digital transformation in an incumbent firm in a traditional sector surrounded by a complex digital ecosystem. Second, in contrast to single hotels, a large hotel chain has the resources to establish an ambitious digital business strategy and invest in digital technology accordingly. When searching for possible organizations, we identified the hotel chain Nordic Choice as an aggressive player, which offered the opportunity to investigate digital transformation in detail.

The research setting was the competitive arena of the hospitality industry, where Online Travel Agencies (OTAs) such as Hotels.com and Booking.com have industrialized a complex digital hospitality ecosystem based on their digital platforms. From the individual traveler's perspective, these platforms provide a convenient hotel booking process typically by listing a destination's available hotel rooms and sorting them under various criteria. This allows for easy price and offerings comparison. This development has led to an increasingly complex distribution environment. For hotels and hotel chains, OTAs came as a mixed blessing. On one hand, they offer an efficient distribution channel in making rooms available on the internet. The service quality of the OTA websites helps introduce new customers to hotels as well [31]. On the other, OTAs position themselves between the guest and the hotel, representing a considerable challenge to the traditional hotel-guest relationship. Moreover, OTAs are reported to charge $15-30 \%$ of the room price for their service [32]. Hotel managers realize that these new actors are changing the rules of competition and thus, threatening the hospitality industry's whole business model.

In 2014, in response to increasing competition from OTAs, and the fear of losing control of their distribution channels and customer relationships, Nordic Choice initiated a digital business strategy. Its vision was to create "the best ecosystem in the Nordic region for digital booking and guest travel experience."

\subsection{Data collection}

This study was based on several data sources (Table 1). We gathered data that covered Nordic Choice's digital transformation process between the years 2014 and 2020. The main data source was the interviews. The primary selection criterion for key informants was personal involvement in implementing the digital business strategy and digital transformation. To gather varied experiences and viewpoints, we chose informants from different parts of the organization and with different roles, such as senior managers, IT managers, department managers, marketing officers, IT personnel, accountants, 
controllers, and receptionists.

\section{Table 1. Overview of the data sources and} their use.

\begin{tabular}{|c|c|c|}
\hline Data source & Data type & Use in analysis \\
\hline $\begin{array}{l}31 \\
\text { interviews }\end{array}$ & $\begin{array}{l}\text { Second-phase } \\
\text { interviews (9) } \\
\text { (2017-2018) } \\
\text { Third-phase } \\
\text { interviews (7) } \\
\text { (2019-2020) }\end{array}$ & $\begin{array}{l}\text { Understand the } \\
\text { participants' perceptions of } \\
\text { the external challenges that } \\
\text { led to the digital } \\
\text { transformation } \\
\text { Understand the informants' } \\
\text { perceptions of the digital } \\
\text { transformation } \\
\text { Understand outcome of the } \\
\text { strategy, challenges, and } \\
\text { plans for the future }\end{array}$ \\
\hline $\begin{array}{l}\text { Archival } \\
\text { data }\end{array}$ & $\begin{array}{l}\text { Digital business } \\
\text { strategy, technical } \\
\text { documentation, } \\
\text { internet statistics, } \\
\text { and accounting } \\
\text { data; online articles }\end{array}$ & $\begin{array}{l}\text { Provide information about } \\
\text { the digital strategy, digital } \\
\text { services offered, digital } \\
\text { architecture, and outcomes } \\
\text { Create a timeline of events } \\
\text { to support and triangulate } \\
\text { the interview data } \\
\text { Understand the digital } \\
\text { transformation }\end{array}$ \\
\hline Observations & $\begin{array}{l}\text { Participation at } \\
\text { internal } \\
\text { conferences, } \\
\text { engagement with } \\
\text { the loyalty } \\
\text { program, hotel } \\
\text { visits, and informal } \\
\text { conversations } \\
\text { Meetings where we } \\
\text { presented the study } \\
\text { to Nordic Choice }\end{array}$ & $\begin{array}{l}\text { Provide insights into } \\
\text { events that could be } \\
\text { investigated further } \\
\text { Support and triangulate the } \\
\text { interview data }\end{array}$ \\
\hline
\end{tabular}

Interviews were conducted in three phases. In the first phase (2016-2017), we conducted 15 interviews to understand the participants' perceptions of the challenges and pressures the firm was confronted with leading up to the digital business strategy and the first activities to implement this strategy. In the second phase (2017-2018), we conducted nine interviews to understand the informants' perceptions and experiences of the strategy, including the establishment of a new digital innovation unit (eBerry), digital projects, and the loyalty program. In the third phase (2019-2020), we conducted seven interviews, in combination with several informal discussions with key players. The purpose of this phase was to understand the results and outcome of the strategy, as well as challenges and plans for the future. The data collection was purposely conducted to span the period immediately before and in parallel with the digital transformation to capture the conditions that led to its development and the actual issues inherent in the transformation.

The interviews were semi-structured and open- ended to capture the informants' perceptions of the digital transformation. We designed an interview guide to cover our topics of interest while allowing exploration of new areas. The main topics discussed were key challenges facing Nordic Choice in the digital hospitality ecosystem; strategic alternatives and choices; the selected technical and organizational solutions; and implementation challenges, outcomes, and plans. In this manner, we tracked the unfolding of events in real time and in retrospect, thus covering the five-year period. Two researchers participated in most of the interviews, which lasted 1.0-1.5 hours. Notes were taken during the interviews, and summaries were then made from those notes. The interviews were also audio-recorded and transcribed verbatim. If necessary, the interviews were complemented with e-mail correspondence to ask supplementary questions or clarify certain points.

We also collected firm-level data from company reports, presentations, and internal documents for the period investigated. The archival documents were used to verify and cross-check the information obtained through the interviews, confirm the timeline's accuracy, and follow up on key concerns and events mentioned during the interviews. In this manner, we triangulated the data sources, which contributes to the trustworthiness of the study.

\subsection{Data analysis}

The data analysis was conducted in six steps (see Table 2).

Table 2. In-depth data analysis.

\begin{tabular}{|l|l|}
\hline Activity & Output \\
\hline $\begin{array}{l}\text { 1: Analyze literature on dynamic } \\
\text { capabilities and socio-technicality }\end{array}$ & $\begin{array}{l}\text { Sociotechnical micro- } \\
\text { foundation concept } \\
\text { (Section 2.3) }\end{array}$ \\
\hline $\begin{array}{l}\text { 2: Analyze case chronology and key } \\
\text { events }\end{array}$ & $\begin{array}{l}\text { Timeline and case } \\
\text { description }\end{array}$ \\
\hline $\begin{array}{l}\text { 3: Analyze and structure case } \\
\text { description according to the three } \\
\text { capacities of dynamic capabilities }\end{array}$ & $\begin{array}{l}\text { Structured case description } \\
\text { on dynamic capabilities } \\
\text { (Section 4) }\end{array}$ \\
\hline $\begin{array}{l}\text { 4: Analyze and identify empirical } \\
\text { sociotechnical micro-foundations in } \\
\text { the case description }\end{array}$ & $\begin{array}{l}\text { Sociotechnical micro- } \\
\text { foundations that enabled } \\
\text { the digital transformation } \\
\text { (Section 4, examples in } \\
\text { Table 3) }\end{array}$ \\
\hline $\begin{array}{l}\text { 5: Assess the usefulness of the } \\
\text { sociotechnical micro-foundation } \\
\text { concept in empirical digital } \\
\text { transformation studies }\end{array}$ & $\begin{array}{l}\text { Confirm relevance of the } \\
\text { sociotechnical micro- } \\
\text { foundation concept }\end{array}$ \\
\hline $\begin{array}{l}\text { 6: Posit findings in a theoretical } \\
\text { framework }\end{array}$ & $\begin{array}{l}\text { Answer to research } \\
\text { question (Section 5, Table } \\
\text { 4, Figures 1 and 2) }\end{array}$ \\
\hline
\end{tabular}

In the first step, we analyzed literature on dynamic capabilities and socio-technicality, to develop the concept of sociotechnical micro-foundations. Then, in the second step, we analyzed the case chronology and key events provided by the interview transcripts and supporting data sources, and constructed a timeline and 
case description in light of the digital transformation. Building on dynamic capability theory [6, 7], in the third step, we analyzed the case description according to the three phases sensing, seizing, and reconfiguring, and then structured the case description accordingly. In the fourth step, we analyzed the case description and applied open coding to identify the sociotechnical micro-foundations that enabled the dynamic capabilities throughout the digital transformation. We analyzed the case description several times based on our sociotechnical micro-foundation concept, until no new items were found. We worked independently, compared findings, and reconciled them.

In the fifth step, we assessed the usefulness of the sociotechnical micro-foundation construct by reviewing empirical digital transformation studies. In the sixth step, we conceptualized and theorized the findings in a theoretical framework for sociotechnical micro-foundations by abstracting the empirical findings into higher-level sociotechnical micro-foundations; thus, we provided an answer to the research question.

\section{Results}

In this section, we draw on the dynamic capability literature to unbundle Nordic Choice's digital transformation and identify the sociotechnical microfoundations that enabled it. We present the findings chronologically based on the three capacities sensing, seizing, and reconfiguration and highlight the sociotechnical micro-foundations that enabled the digital transformation. Table 3 provides examples of sociotechnical micro-foundations discussed in the following text.

Table 3. Examples of sociotechnical microfoundations.

\begin{tabular}{|l|l|l|}
\hline $\begin{array}{l}\text { Sensing } \\
\mathbf{( 2 0 1 4 - 2 0 1 5 )}\end{array}$ & $\begin{array}{l}\text { Seizing } \\
\mathbf{( 2 0 1 6 - 2 0 1 7 )}\end{array}$ & $\begin{array}{l}\text { Reconfiguring } \\
\mathbf{( 2 0 1 8 - 2 0 2 0 )}\end{array}$ \\
\hline $\begin{array}{l}\text { Management } \\
\text { analyzed the } \\
\text { internet to } \\
\text { understand the } \\
\text { hospitality } \\
\text { ecosystem and } \\
\text { identified OTAs as } \\
\text { a threat. }\end{array}$ & $\begin{array}{l}\text { Vice president } \\
\text { analyzed } \\
\text { technology trends } \\
\text { to develop a digital } \\
\text { business strategy. }\end{array}$ & $\begin{array}{l}\text { eBerry redesigned } \\
\text { the loyalty } \\
\text { program to } \\
\text { influence customer } \\
\text { behavior. }\end{array}$ \\
$\begin{array}{l}\text { Management } \\
\text { analyzed } \\
\text { technology trends } \\
\text { to detect the gap } \\
\text { between existing } \\
\text { and needed digital } \\
\text { capabilities. }\end{array}$ & $\begin{array}{l}\text { optimize Google } \\
\text { visibility. }\end{array}$ & $\begin{array}{l}\text { eBerry utilized } \\
\text { novel technology } \\
\text { to innovate new } \\
\text { digital services. }\end{array}$ \\
\hline
\end{tabular}

\subsection{The sensing phase (2014-2015)}

For years, Nordic Choice had considered OTAs as valuable partners that offer an effective marketing and distribution channel. In 2014, by analyzing the internet to understand the hospitality ecosystem, management identified OTAs as a threat. The OTA platforms were challenging Nordic Choice's business model on two levels. First, the increasing number of bookings through online intermediaries led to price pressure and lower margins. Nordic Choice Vice President Bjørn Arild Wisth stated, "The past decade had changed our communication with the customers. First, in the 1990s, the online booking websites, such as Hotels.com and Booking.com, emerged. We then regarded them as helpful add-ons [that made] it easier to find us, but got worried when their share of the room price got greedy. Over time, an increasing share of our customers communicated with these sites and not with us. I realized that if nothing were done, we would end up as a commodity provider of hotel rooms, leaving the distribution to the internet companies. This was a threat to our whole business model."

Second, by dealing directly with customers, OTAs also accumulate the information needed to manage customer relationships. The CDO stated, "We had to face the tough insight that we had lost control over our distribution and customer data."

Thus, management sensed that they had to act. After numerous discussions about how to respond, in 2014 management decided to initiate a digital transformation. However, by analyzing technology trends and their own capabilities, management detected there was a gap between existing and needed digital capabilities. The existing IT department functioned as a traditional service provider designed solely for maintaining the existing infrastructure, which was old and inadequate. Moreover, the booking website was outdated, unstable, and outsourced to an external provider.

\subsection{The seizing phase (2016-2017)}

The digital transformation initiative consisted of three main parts. First, the vice president analyzed technology trends to develop a digital business strategy. The vision was to create the best ecosystem in the Nordic countries for the digital booking and guest travel experience, with the aim of securing Nordic Choice's position in the future distribution landscape. Second, to strengthen the hotelcustomer relationship, management decided to launch a loyalty program. Third, because the existing IT department was unable to realize a digital business strategy, management decided to establish a new digital innovation unit with the mandate to lead the digital transformation and implement the stated vision.

In late 2015, Nordic Choice hired a CDO and established the new digital innovation unit, eBerry, in 
January 2016 as a separate company. To renew its existing digital resources, eBerry engaged 40 new IT experts. eBerry immediately started strategizing its position in the ecosystem by entering the digital competition arena and implementing three short-term initiatives. First, eBerry utilized booking data to renegotiate the contracts with the OTAs and managed to reduce their share of the room price substantially. Second, an analytics team was created, utilizing analytics to continuously monitor the digital ecosystem. Moreover, the analytic team developed search optimization algorithms to optimize Google visibility in real time. A technician said, "What we do a lot is to ensure that we are in the right places, so that when people are out looking and want to book a hotel, they are driven towards us."

Third, to develop the new digital services, eBerry initiated three projects: one to develop a customer app that was aligned with the loyalty program, one to redesign the old website, and one to establish a new digital infrastructure. The website was consequently insourced. Moving from a relatively simple booking system into the digital hospitality ecosystem was challenging. The CDO commented: "Legacy systems are a big challenge, both the six-year-old web solution and the old booking systems. We need a flexible platform, which is difficult to create. In addition, recruiting top competence is challenging. The traditional hotel culture is not congruent with the young IT geeks we are recruiting."

eBerry sensed that it also had to compete with OTAs for customer information, as the relationship between OTAs and Nordic Choice in this regard was deeply asymmetric in favor of the OTAs. The OTAs had access to vast amounts of information, such as customer preferences, reviews, and actions. In addition, OTAs had access to Google search histories and had developed sophisticated software that traces the actions of potential customers to place clickable offers in emails. eBerry had access to much less information, although it had, of course, the details of previous bookings and the profiles of established customers from the customer relationship management system.

To mitigate this disadvantage, Nordic Choice instigated a "second visit" strategy: accepting that a relatively large share of first-time customers would book through OTAs. However, arriving customers should always be offered membership in the Nordic Choice loyalty program. To support the second visit strategy, increase the firm's online presence, and collect information about customer behavior, eBerry developed a customer app to launch the loyalty program. The first version supported standard hospitality functions, such as booking and check-in/check-out. To enable an easy and convenient booking experience, it was decided not to require payment in advance. The app's functionality aligned with the offerings and benefits in the loyalty program and provided eBerry valuable information about hotel guests' behaviors and preferences. Thus, eBerry analyzed how its customers were using its website and app daily. The benefit for Nordic Choice was direct contact with customers and always reminding them that the easiest and cheapest way to book was through the Nordic Choice app or website.

To connect the website and the customer app, eBerry's infrastructure team established a robust internal digital platform (Omni) and developed APIs to connect existing and new systems. The objective was to build a platform that provided the website and the customer app equal booking functionality. From a customer perspective, the choice of a digital channel should be transparent. A robust and functional platform was also considered imperative to competing in the digital hospitality ecosystem.

\subsection{The reconfiguring phase $(2018-2020)$}

The digital transformation, involving eBerry, the redesigned website, the customer app, the loyalty program, and the second visit strategy, enabled Nordic Choice to maintain the main share of bookings through its own distribution channels. From a management perspective, the results from the seizing phase are satisfactory:

- The loyalty program gained 2.2 million members, and the app has 254,000 downloads.

- The revenue from booking through Nordic Choice's digital channels (website and app) was 210 million euros, representing a $78 \%$ increase in digital bookings since 2016 .

- The booking costs through Nordic Choice's digital channels are $3 \%$ of the price compared to $15-20 \%$ using an OTA.

- The ongoing competition in the digital ecosystem is handled by Nordic Choice's own expertise.

However, the hotel chain's management realized that the digital transformation did not stop there. By constantly monitoring the digital ecosystem, management realized that the competition in the digital landscape was constantly changing: The OTAs were continuously developing their business tactics and introduced new services frequently, and new actors were regularly arriving in the digital landscape. Nordic Choice handles these challenges at the strategic, tactical, and operational levels.

At the strategic level, management and the Nordic Choice board frequently assess the OTAs' activities and services. Managers also follow the Skift website (industry) and participate in international forums. This allows them to continuously consider and reconsider their strategic positioning in the digital hospitality ecosystem.

At the tactical level, by focusing on direct communication with customers, eBerry redesigned the 
loyalty program (and the app) to influence customer behavior. A broad campaign in 2018 encouraged travelers to book with Nordic Choice directly. For example, when a customer who once booked through one of the OTAs wished to register Nordic Choice bonus points, the check-in staff told her that no bonus points were earned if the booking was done through OTAs, nor could she receive a free newspaper as is typical for customers who booked through Nordic Choice directly. In addition, large advertising sign campaigns were arranged to stimulate customers to book rooms directly through the guest app. At the operational level, and to realize the vision of "the best ecosystem in the Nordics for digital booking and guest travel experience," eBerry continued utilizing novel technology to innovate new digital services. In 2018, new functions were included in the customer app, such as mobile room keys, in-stay feedback, guest chat solutions, loyalty program functions, and a personal history function. Self-service check-in/check-out kiosks were installed in hotel lobbies. The objective of the digital guest solutions was to support guests pre-, in, and post-stay and implement the hotel chain's vision of a digital guest journey. Thus, eBerry established a company-wide campaign to motivate and train desk personnel in digital routines to align their practices with the digital guest solutions. A receptionist at a Stockholm hotel stated, "We have been participating in the eBerry kick-off, and got quite excited about the solutions. Actually, I applied for a position at Nordic Choice because I perceive them as the most innovative chain in the business. It is not only the technology, which is fine, but also the energy in the organization." At the same time, the infrastructure team redesigned APIs to integrate the new digital services.

Nordic Choice's digital transformation has been ongoing since January 2016, and its short-term goal of maintaining the main share of the firm's bookings in the distribution chain has been achieved. However, the high ambition of the eBerry initiative, expressed as "creating the best ecosystem in the Nordics for digital booking and guest travel experience," is a long-term goal. The digital transformation is fully supported and fronted by owner Petter Stordalen and senior management.

At a large in-house conference in 2019 for the chain's employees the researchers attended, Stordalen even presented the firm's digital ambitions: "The competition is extremely hard. We have to take part in the digital transformation and respond to our guests' changing needs and requirements. We are already investing heavily in digital technology and will continue to do so. No hotel chain will invest more in technology than us: our app, our website, and in our hotels. One of our competitors said to me, 'We have completed our technology investments.' My response to him was, 'If you think you are finished, then you are indeed finished.' My message today is, we have just started.”

\section{Discussion}

Digital transformation is a challenging and risky process, involving new business models and often creating a new organizational identity [19]. In the Nordic Choice case, the distribution model was fundamentally changed, and the eBerry initiative created a new identity. How was this accomplished? Or put differently, which mechanisms enable firms to engage with digital transformations to build and sustain a competitive advantage? [5].

In developing the sociotechnical micro-foundations concept, we investigated the "cogs and wheels" of digital transformation, i.e., the specific actions needed to translate strategic visions into results. The findings highlight that conducting a digital transformation requires the development of micro-foundations that integrate organizational abilities and digital resources [1]. Based on the sociotechnical perspective in which organizations are not purely social but interacting networks of people and technology, we call these integrated abilities sociotechnical micro-foundations. In this study, we identified continuous sensing, seizing, and reconfiguring activities; however, it was the development of sociotechnical micro-foundations that proved essential for realizing Nordic Choice's vision of a digital guest journey and goal of maintaining the primary share of bookings through the firm's own digital channels. The investigation illustrated repeatedly how capacities and technologies were combined throughout the transformation process. Thus, the case analysis shows the concept's usefulness. A review of empirical studies on digital transformation confirmed its relevance [8, 33].

However, to apply the sociotechnical microfoundations concept in practice and support further theoretical development, we need to theorize a full framework. This returned us to the research question: How can we conceptualize and theorize a sociotechnical micro-foundation concept?

\subsection{A framework for sociotechnical micro- foundations}

Based on our review of the literature and analysis of the case, we propose a framework for sociotechnical micro-foundations. Our objective is twofold. First, we seek to advance the literature on dynamic capabilities, which has been criticized for being vague and elusive [34], as well as abstract and intractable [35]. A major challenge has been to distinguish between higher-level capabilities and underlying operational capacities [36], and there have been further calls to engage with microactivities that support capabilities [37]. Second, we aim at extending the digital transformation literature by 
revealing the micro-level mechanisms necessary for building and maintaining dynamic capabilities for the transformation [5]. This will help us understand how the digital transformation process is brought forward by combining organizational competencies and digital resources, and how these micro-foundations are aligned within higher-level dynamic capabilities [8].

We define the basic concepts of the sociotechnical micro-foundations construct. Based on the literature review and case analysis, we propose sociotechnical micro-foundations as consisting of three conceptsactors, actions, and resources - which we decompose as follows. First, we decompose the actors concept, based on our observations and those of Felin et al. [24], into three constituent components: individuals, processes, and structures. This implies that capacities for digital transformation may be delegated to and enacted by actors individually or by groups of people interacting in processes (sequence of interdependent events) or organizational structures (e.g., work groups, projects, departments). Second, based on our observations and the premise that micro-foundations involve a performative aspect [38], we propose a set of generic (but not exclusive) actions for each dynamic capability step, such as sensing (analyzing, identifying), seizing (developing, innovating, establishing, launching), and reconfiguring (redesigning). Third, we decompose resources, following [39] and our observations, into four components: data, software algorithms, digital platforms, and digital ecosystems. This implies that digital resources exist at various levels and require different actors and actions be handled effectively. The three concepts and their underlying components are summarized in Table 4.

Table 4. The concepts and components of sociotechnical micro-foundations.

\begin{tabular}{|c|c|c|c|}
\hline & Actors & Actions & Resources \\
\hline \multirow{7}{*}{ Components } & Individuals & Analyzing & Data \\
\hline & Processes & Identifying & Software \\
\hline & Structures & Developing & algorithms \\
\hline & & Innovating & Digital \\
\hline & & Establishing & platforms \\
\hline & & Launching & Digital \\
\hline & & Redesigning & ecosystems \\
\hline
\end{tabular}

Sociotechnical micro-foundations can be configured in various ways, as shown in Figure 1. For example, a firm may nominate an individual to analyze a dataset, a process for identifying a digital ecosystem, and a structure for innovating a digital platform. Over time, and based on experience and new knowledge [36], sociotechnical micro-foundations may be reconfigured.

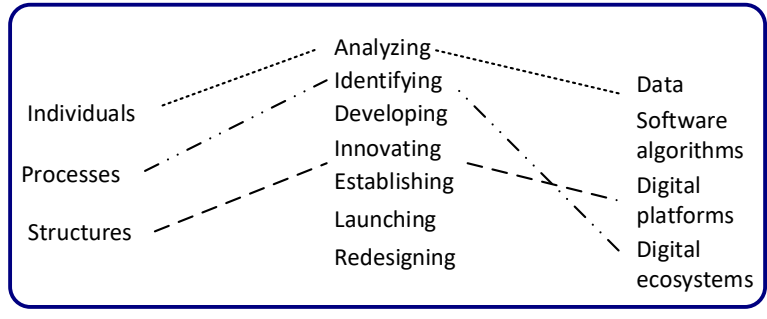

\section{Figure 1. Combinations of sociotechnical concepts and their components.}

Numerous configurations are possible in this framework. We illustrate its usefulness in a generalized configuration built on the Nordic Choice case (Figure 2). The configuration is shown with three levels. To the right, the highest level is the digital transformation, typically characterized as a major organizational change driven by, built on, or enabled by digital technology, altering how business is conducted. The digital transformation is enabled through three capacitiessensing, seizing, and reconfiguring - which constitute the middle level. At the bottom are the sociotechnical micro-foundations, defined as "the combination of an organizational competencies and digital resource that enables the organization to realize a specific type of task," needed to support and sustain each of the three capacities, constituting the lowest level.

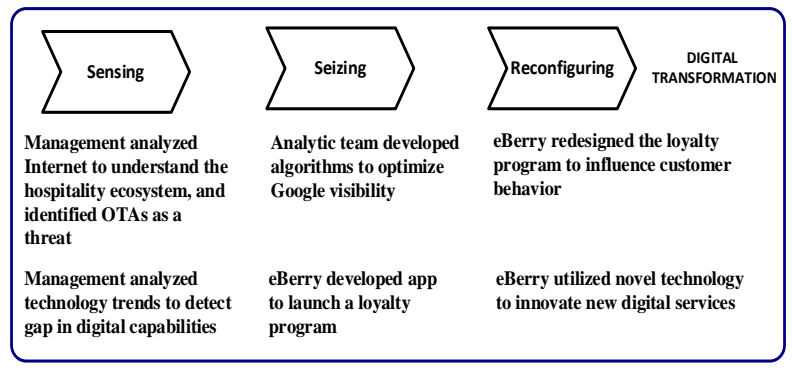

\section{Figure 2. Generalized configuration built on Nordic Choice.}

The configuration illustrates that to sense, Nordic Choice established sociotechnical micro-foundations that enabled management to understand the digital ecosystem and identify OTAs as a threat, and to detect a gap in the firm's digital capabilities by analyzing technology trends. To seize, the analytic team developed algorithms to optimize Google visibility, and eBerry developed a customer app to launch a loyalty program. To reconfigure, eBerry redesigned the loyalty program (and the app) to influence customer behavior, and eBerry utilized novel technology to innovate new digital services.

As illustrated above, the sociotechnical microfoundations concept helped us disentangle the underlying practices of digital transformation that are close to the 
actual work organizational actors, including managers, perform in the digital transformation process.

According to dynamic capability theory, microfoundations must be developed and managed; they do not appear from nothing [24, 36, 38]. What this study brings is the perspective that firms must develop microfoundations that combine organizational abilities and digital technologies. In a digital transformation, these phenomena are not isolated and thus, should not be handled separately. This empirical study provides evidence that it is this sociotechnical combination that ensures progress. Thus, the proposed framework builds on previous insights $[10,11]$.

Building on this perspective, this framework provides firms a simple yet powerful representation of the interdependent nature of capacities for digital transformation. The value of applying the sociotechnical micro-foundation framework is that it gives organizations a structured and systematic way of identifying and establishing interrelated sociotechnical capacities. The framework is flexible and can be applied by digital transformation programs in various contexts. The sociotechnical micro-foundations may be configured to the specific needs of the organization and its ecosystem's characteristics. The relevant types of skills and technologies differ, as this case study and the literature review illustrate.

\subsection{Limitations and future research}

Several study limitations should be mentioned. First, the research design involved a sample of only one case. Thus, we do not claim that we have discovered all socio-technical micro-foundations involved in digital transformation. Moreover, the data was collected from a company during its expansion and that was financially well-equipped to create digital initiatives and conduct a digital transformation. This certainly influenced the company's ambitions, initiatives, and outcomes. Future research should address these limitations.

\section{Conclusions}

Responding to a call in the literature to explore the role of dynamic capabilities in digital transformation [5], we investigated the research question, how can we conceptualize and theorize a sociotechnical microfoundation concept? Building on the dynamic capabilities approach, we developed and assessed the concept through an analysis of the digital transformation of a hotel chain. Our contribution is a framework for sociotechnical micro-foundations, showing in detail how combinations of actors, actions, and digital resources constitute necessary foundations for digital transformation. In doing so, we extend the digital transformation literature by revealing the micro- level mechanisms necessary for building and maintaining dynamic capabilities for the transformation.

\section{References}

[1] A. Bharadwaj, O.A. El Sawy, P.A. Pavlou, and N. Venkatraman. "Digital business strategy: Toward a next generation of insights.” MIS Quarterly, 2013, pp. 471-82.

[2] S. Berghaus and A. Back. "Disentangling the fuzzy front end of digital transformation: Activities and approaches." Paper presented at the 38th International Conference on Information Systems (ICIS), Seoul, South Korea, 2017.

[3] G. Westerman, D. Bonnet, and A. McAffe. Leading Digital. Turning Technology into Business Transformation. Harvard Business Review Press, Boston, 2014.

[4] E. Piccinini, R.W. Gregory, and L. Kolbe. "Transforming industrial business: The impact of digital transformation on automotive organization." Paper presented at the 36th International Conference of Information Systems, Fort Worth, TX, 2015.

[5] G. Vial. "Understanding digital transformation: A review and a research agenda." Journal of Strategic Information Systems, 2019, pp. 118-144.

[6] D.J. Teece, G. Pisano, and A. Shuen. "Dynamic capabilities and strategic management." Strategic Management Journal, 1997, pp. 509-533.

[7] D. J. Teece. "Explicating dynamic capabilities: The nature and microfoundations of (sustainable) enterprise performance." Strategic Management Journal, 2007, pp. 1319-1350.

[8] A. Yeow, C. Soh, and R. Hansen. "Aligning with new digital strategy: A dynamic capabilities approach." Journal of Strategic Information Systems, 2018, pp. 43-58.

[9] I. Barreto. "Dynamic capabilities: A review of part research and an agenda for the future." Journal of Management, 2010, pp. 256-280.

[10] B. Niehaves, R. Plattfaut, and S. Sarker. "Understanding dynamic IS capabilities for effective process change: A theoretical framework and an empirical application." Paper presented at the International Conference on Information Systems, Shanghai, China, 2011.

[11] M.H. Jensen and L. Bækgaard. "An explorative study of socio-technical information systems capabilities." Paper presented at the 39th Information Systems Research Conference in Scandinavia, IRIS, Ljungskile, Sweden, 2016.

[12] O. Henfridsson and B. Bygstad. "The generative mechanisms of digital infrastructure evolution." MIS Quarterly, 2013, pp. 907-931.

[13] K. Osmundsen, J. Iden, and B. Bygstad. "Digital transformation: Drivers, success factors, and implications." Paper presented at the 12th Mediterranean Conference on 
Information Systems (MCIS), Corfu, Greece, 2018.

[14] I. Haffke, B.J. Kalgovas, and A. Benlian. "The role of the cio and the CDO in an organization's digital transformation." Paper presented at the 37th International Conference on Information Systems (ICIS 2016), Dublin, Ireland, 2016.

[15] J. Butschan, S. Heidenreich, B. Weber, and T. Kraemer. "Tackling hurdles to digital transformation - the role of competences for successful Industrial Internet of Things (IIoT) implementation.” International Journal of Innovation Management, 2018, pp. 1-34.

[16] P. Feher and K. Varga. "Using design thinking to identify banking digitization opportunities - Snapshot of the Hungarian banking system." In: Bled eConference, Bled, Slovenia, pp. 151-168, 2017.

[17] G.C. Kane, D. Palmer, A.N. Phillips, D. Kiron, and N. Buckley. "Achieving Digital Maturity. Adapting your company to a changing world." MIT Sloan Management Review. Research report, 2017, pp. 1-31.

[18] L. Heilig, S. Schwarze, and S. Voß. "An analysis of digital transformation in the history and future of modern ports." In: Proceedings from HICSS 2017, 2017, pp. 13411350.

[19] L.K. Wessel, A. Baiyere, R. Ologeanu-Taddei, J. Cha, and T.B. Jensen. "Unpacking the difference between digital transformation and it-enabled organizational transformation." Journal of the Association for Information Systems, 2020.

[20] D.A. Gioia, R. Nag, and K.G. Corley. "Visionary ambiguity and strategic change: The virtue of vagueness in launching major organizational change." Journal of Management Inquiry, 2012, pp. 364-375.

[21] C.E. Helfat, S. Finkelstein, W. Mitchell, M.A. Peteraf, H. Singh, D.J. Teece, and S.G. Winter. Dynamic Capabilities: Understanding Strategic Change in Organizations. Blackwell, London, 2017.

[22] R. Singh, L. Mathiassen, M.E. Stachura, and E.V. Astapova. "Dynamic capabilities in home health: IT-enabled transformation of post-acute care." Journal of the Association for Information Systems, 2011, pp. 163-188.

[23] R. Amit and P.J.H. Schoemaker. "Strategic assets and organizational rent." Strategic Management Journal, 1993, pp. 33-46.

[24] T. Felin, N.J. Foss, K.H. Heimeriks, and T.L. Madsen. "Microfoundations of routines and capabilities: Individuals, processes, and structures." Journal of Management Studies, 2012, pp. 1351-1374.

[25] L. Fallon-Byrne and B. Harney. "Microfoundations of dynamic capabilities for innovation: A review and research agenda.” The Irish Journal of Management, 2017, pp. 21-31.

[26] M. Govers and P. van Amelsvoort. "A socio-technical perspective on the digital era: The Lowlands view." The European Journal of Workplace Innovation, 2019, pp. 142-
159.

[27] O. Volkoff and D.M. Strong. "Critical realism and affordances: Theorizing IT-associated organizational change processes.” MIS Quarterly, 2013, pp. 819-834.

[28] M.D. Myers. "Qualitative research in information systems.” MIS Quarterly, 1997, pp. 241-242.

[29] A. Langley. "Strategies for theorizing from process data." Academy of Management Review, 1999, pp. 691-715.

[30] C. Welch and E. Paavilainen-Mäntymäki. "Putting process (back) in: Research on the internationalization process of the firm." International Journal of Management Reviews, 2014, pp. $2-23$.

[31] Y.W. Chang, P.Y. Hsu, and Y.C. Lan. "Cooperation and competition between online travel agencies and hotels." Tourist Management, 2019, pp. 187-196.

[32] E. Feinstein. "OTA's vs. direct hotel bookings: Which is the leading trend for 2018?" TravelDailyNews, https://www.traveldailynews.com/post/otas-vs-direct-hotelbookings-which-is-the-leading-trend-for-2018

[33] F. Svahn, L. Mathiassen, and R. Lindgren. "Embracing digital innovation in incumbent firms: How Volvo cars managed competing concerns." MIS Quarterly, 2017, pp. 239253, 2017.

[34] M. Kraatz and E. Zajac. "How organizational resources affect strategic change and performance in turbulent environments: Theory and evidence." Organization Science, 2001, pp. 632-657.

[35] E. Danneels. "Organizational antecedents of second-order competences." Strategic Management Journal, 2008, pp. 519543.

[36] A. Kuuluvainen. "How to concretize dynamic capabilities? Theory and examples." Journal of Strategy and Management, 2012, pp. 381-392.

[37] O. Schilke, S. Hu, and C.E. Helfat. "Quo vadis, dynamic capabilities? A content-analytic review of the current state of knowledge and recommendations for future research." Academic Management Annals, 2018, pp. 390-439.

[38] M.S. Feldman and B.T. Pentland. "Reconceptualizing organizational routines as a source of flexibility and change." Administrative Science Quarterly, 2003, pp. 94-118.

[39] O. Henfridsson, J. Nandhakumar, H. Scarbrough, and N. Panourgias. "Recombination in the open-ended value landscape of digital innovation." Information and Organization, 2018, pp. 89-100. 